\title{
Latitudinal diversity patterns of Chilean coastal fishes: searching for causal processes
}

\author{
Arturo H Navarrete ${ }^{1}$, Nelson A Lagos ${ }^{2}$ and F Patricio Ojeda ${ }^{1 *}$
}

\begin{abstract}
Background: Several particular aspects of diversity patterns of Chilean littoral fishes are still poorly understood, and existing studies within this scope are fundamentally based on bibliographic compilations. In this study, we use empirical data to assess whether the diversity patterns of fish fauna along $4000 \mathrm{~km}$ of the Chilean coast $\left(20^{\circ}-55^{\circ} \mathrm{S}\right)$ can be explained in relation to the environmental latitudinal gradient. Fish were collected from intertidal pools and subtidal habitats $(<35 \mathrm{~m})$. Analyses focused on the spatial scales of diversity patterns and latitudinal breaks in species diversity, comparing the observed patterns among intertidal and subtidal habitats. Correlations between variance in environmental factors and species richness were calculated.

Results: Richness was positively autocorrelated at spatial scales $<1000 \mathrm{~km}$. Overall, richness was observed to progressively decrease toward higher latitudes, but values for intertidal fish in particular decreased towards the north and south from the point of maximum richness. This is a pattern that has already been recorded for other intertidal organisms. Similarity was seen to decrease with distance, and turnover point for intertidal fishes was high around $30^{\circ}-32^{\circ} \mathrm{S}$, while northern species disappeared between $36^{\circ}-39^{\circ} \mathrm{S}$. Subtidally, there is an invasion of subantarctic species between $53^{\circ}-55^{\circ} \mathrm{S}$.
\end{abstract}

Conclusions: Environmental variables are significant to the diversity patterns recorded. However, richness variations could result from many types of variables acting together and not from one single factor.

Keywords: $a$ and $\beta$-diversity; Endemic species; Intertidal fishes; Latitudinal diversity gradient; Marine biogeography

\section{Background}

Species richness is the fundamental and most intuitive expression of biological diversity and represents the number of coexisting species (i.e., with overlapping ranges) on a particular spatial scale (Magurran 2004). Despite its apparent simplicity, spatial variation in the number of species in the latitudinal gradient generates one of the canonical patterns in ecology (Blackburn and Gaston 1996), where it is shown that richness increases towards the tropics in a wide variety of taxa (Rosenzweig 1995). Notwithstanding these wellknown latitudinal patterns of species richness, the mechanisms associated with their generation still remain unclear. For a couple of decades, several studies have changed the traditional focus of analysis of local species richness, or $\alpha$ diversity (e.g., Harrison et al. 1992; Blackburn and Gaston

\footnotetext{
* Correspondence: pojeda@bio.puc.cl

'Departamento de Ecología, Facultad de Ciencias Biológicas, Pontificia Universidad Católica de Chile, Almeda 340, Casilla 114-D, Santiago, Chile Full list of author information is available at the end of the article
}

1996; Koleff and Gaston 2002; Rodríguez and Arita 2004; Qian et al. 2005; Soininen et al. 2007), and highlighted the need for additional research on species turnover across local habitat, or $\beta$-diversity (Whittaker 1972). The study of species turnover helps to better describe the dynamics of diversity between communities, which allows a better estimate than studying only $\alpha$-diversity (Soininen et al. 2007). This is why complementary analyses of $\alpha$ and $\beta$-diversity can help with the understanding and identification of the underlying processes that control diversity patterns at different spatial scales as well as promote the development of hypotheses related to general patterns of diversity (Ricklefs 1987; Castilla et al. 2004).

The coast of Chile has received much attention from scientists interested in studying biogeographic patterns in both its flora and fauna (e.g., Sebens and Paine 1979; Santelices 1980; Jaramillo 1982; Brattström and Johanssen 1983; Brattström 1990; Lancellotti and Vásquez 2000; Ojeda et al. 2000; Thiel 2002; Valdovinos et al. 2003; Moreno et al. 2006; Fernández et al. 2009; Broitman et al. 
2011; Rivadeneira et al. 2011; and see Miloslavich et al. 2011 on the marine biodiversity of South America). This can be explained by a series of particular characteristics of the Chilean littoral, most notably its long latitudinal extension of approximately 4,200 $\mathrm{km}$ of coastline (Ojeda et al. 2000), which is strongly influenced by the Humboldt Current System (Thiel et al. 2007). In addition, the Chilean coast has marked differences within its length. It is practically continuous and fully exposed to the prevailing southwesterly winds from Arica (18 $\left.20^{\prime} \mathrm{S}\right)$ to the northern part of Chiloé Island (ca. $41^{\circ} 45^{\prime} \mathrm{S}$ ), while from Chiloé to Cape Horn (ca. $56^{\circ} \mathrm{S}$ ), it is highly fragmented, forming a large number of islands and protected channels (Ahumada et al. 2000; Ojeda et al. 2000), thus representing one of the regions with the highest amount of intertidal habitat in the world (Pequeño et al. 1995). These characteristics create a sharp temperature gradient and a wide variability of current, wind-induced upwelling conditions and environments along the latitudinal axis (Ahumada et al. 2000; Broitman et al. 2001; Camus 2001; Thiel et al. 2007). Such factors could affect the geographic distribution and abundance of the organisms that inhabit it, influencing the observed patterns of diversity.

Although most biogeographic studies conducted on the Chilean coast gather bibliographic information that includes studies using different criteria and methodologies, both for selecting target groups and for analyzing data, these studies generally recognize two faunal groups (Camus 2001), a warm temperate region north of $42^{\circ} \mathrm{S}$ and a cold temperate region south of $42^{\circ} \mathrm{S}$. Furthermore, between these two regions (between $30^{\circ} \mathrm{S}$ and $42^{\circ} \mathrm{S}$ ), the existence of a transition area and species mix has been proposed (Dahl 1960; Dell 1971; Brattström and Johanssen 1983). However, the fact that measures of diversity are scale-dependent (Lopez De Casenave et al. 2007) leads us to interpret the results of studies based on bibliographic compilations with caution, precisely because of differences in the methodologies used for data collection.

Ojeda et al. (2000) put together an extensive bibliographic database with unpublished personal data, to understand the biogeography of marine fish from the Southeast Pacific. They found that littoral fish diversity remains fairly constant along the coast down to around $40^{\circ} \mathrm{S}$, declining south of this latitude. They detected two biogeographic regions along the Chilean coast, with a break between them at $40^{\circ} \mathrm{S}$. In the present study, our goal was to continue with this work by using empirical fish data from rocky intertidal and subtidal habitats through standardized methodologies, thus providing great interpretative value to our results, as it keeps the sampling error term constant. This also avoids, for example, the potential bias implicit in data from bibliographic compilations (i.e., avoiding methodological differences), which has also been done by other recent studies (see Thiel 2002; Häussermann and Försterra 2005; Rivadeneira et al. 2011).

Our objectives were to determine the existence of latitudinal patterns in the richness (i.e., $\alpha$-diversity) and turnover (i.e., $\beta$-diversity) of rocky intertidal and subtidal fish species off the coast of Chile. Additionally, we assessed whether such patterns can be explained by the latitudinal gradient, determining which spatial scales dominate these patterns of variation. Finally, we tried to identify whether there are breaks in richness patterns, assessing whether they are related independently or associated to the environmental variables representative of Chile's coastal ocean and/or to the result of colonization, dispersal, and adaptation processes of ancestral fish taxa that gave rise to what we now recognize as the fish fauna of the Chilean littoral.

\section{Methods}

This paper employs a long and detailed database compiled by FPO from 1970 to 2005, which includes 14 study sites on the rocky Chilean coast spanning about $4,000 \mathrm{~km}$ (Figure 1A), from $20^{\circ} \mathrm{S}$ (Iquique) to $55^{\circ} \mathrm{S}$ (Navarino Island). At each site, the individual specimens collected were identified and the local richness was recorded for littoral fish from both rocky intertidal and subtidal habitats up to 35-m deep (Table 1). Our fish database was also complemented and checked with similar studies conducted along the Chilean coast (see also Moreno and Jara 1984; Varas and Ojeda 1990; Berrios and Vargas 2000; Pérez-Matus et al. 2007).

Fish data are available in the FIP Project no. 2004-28 in the website of the Fondo de Investigación Pesquera (http:// www.fip.cl/Archivos/Hitos/Informes/inffinal\%202004-28. pdf).

\section{Sampling}

In this study, we consider intertidal fishes to be those that live their postlarval lives, or part of them, in the intertidal zone (see Gibson and Yoshiyama 1999). These fishes were collected from rocky intertidal pools at each study site. Sampling consisted of suctioning off the water contained in the pool during the tidal ebb by using a 5 HP portable water pump. The hose nozzle was placed perpendicularly at the bottom of the pool to prevent the fish from being sucked up by the pump. Once the water was extracted, BZ 20 benzocaine fish anesthetic was applied both in the crevices and under the rocks, facilitating capture with hand nets (Hernández-Miranda and Ojeda 2006).

Subtidal fish samplings were conducted by visual surveys along bathymetric transects between 0 and $35-\mathrm{m}$ deep and with three fish collecting nets $(3 \times 50 \mathrm{~m})$ composed of five panels (graduated sizes of openings 10 to $50 \mathrm{~mm}$ ) placed at random on the bottom, perpendicular 

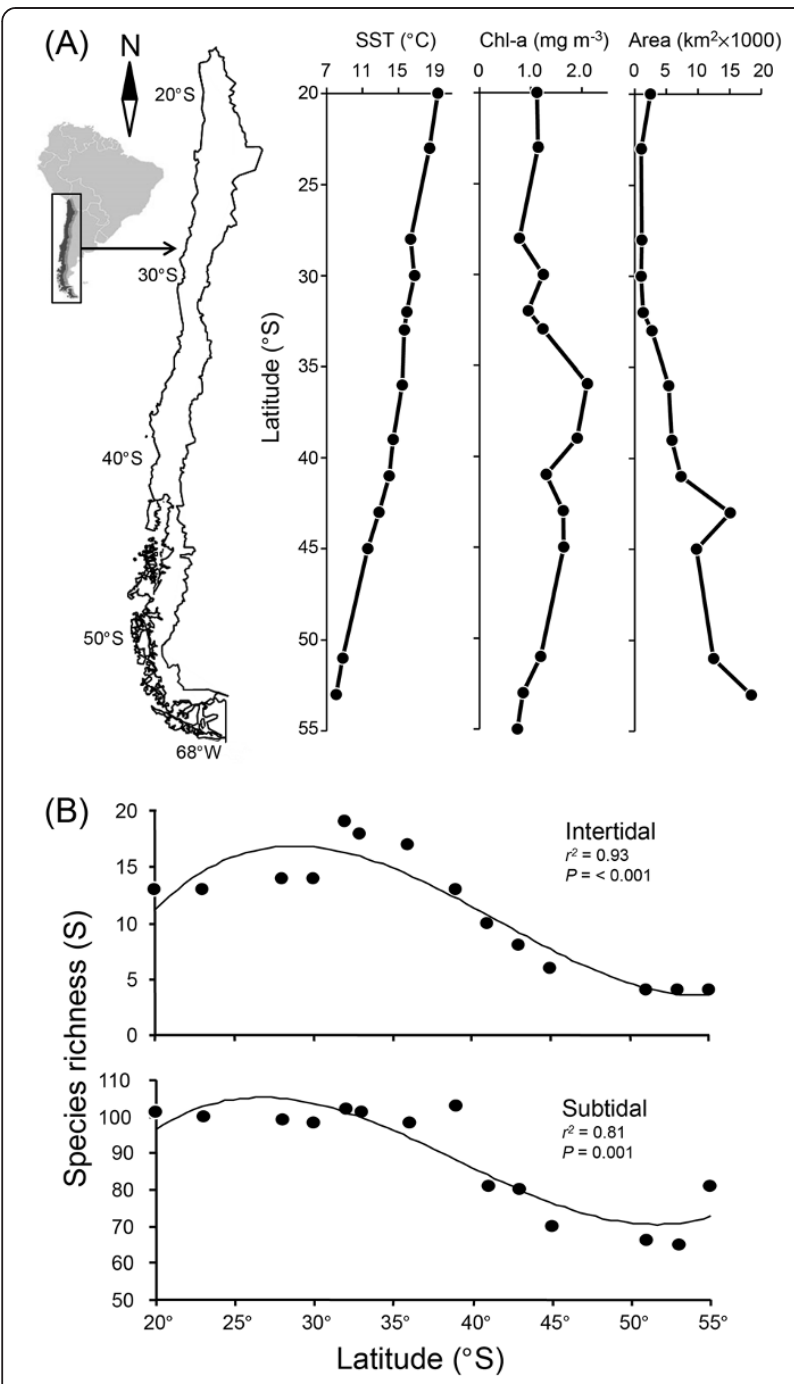

Figure 1 Map of the 14 study sites and patterns of geographic variation. (A) Map of the 14 study sites along the Chilean coast with the corresponding mean values of sea surface temperature (SST), chlorophyll-a concentration (Chl-a), and continental shelf area (Area). (B) Patterns of geographic variation in the species richness inhabiting the intertidal and subtidal up to $35 \mathrm{~m}$. The solid line represents the spatial trend by fitting a third-order polynomial regression.

to the coastline, between 5 and $18-\mathrm{m}$ deep. The nets were placed at the sampling sites $1 \mathrm{~h}$ after sunrise and withdrawn $1 \mathrm{~h}$ after sunset (see Angel and Ojeda 2001).

\section{Latitudinal gradient in species richness}

We conducted a series of regression analyses focused on defining the order in the polynomial regression model between the number of species and latitude-longitude. To do this, first, second, and third order models were sequentially adjusted. The coefficient of determination $r^{2}$ was evaluated to determine the degree of explanation of the latitudinal component on the spatial variation of fish diversity. To rank the models, we use Akaike information criteria (AIC) and the weighted version of the AIC criteria $\left(\mathrm{AIC}_{\mathrm{w}}\right)$ was used to estimate the probabilities of each model being the best model in terms of AIC, given the data and the set of fitted models (Wagenmakers and Farrell 2004).

\section{Spatial scales of autocorrelation of alpha diversity}

Moran's $I$ autocorrelation index was estimated (Sokal and Oden 1978) for different distance classes covering the entire study area. The number of distance classes was selected based on the extent and grain (i.e., separation between sites) obtained with the spatial database. Autocorrelation analysis and construction of correlograms were performed using the SAAP-PC program version 4.3 (Wartenberg 1989), and significance was evaluated using the Bonferroni correction.

\section{Distance decay in similarity of species composition}

Each sampling site can be specified in terms of the composition of species present in it, as well as its spatial position or particular geographic coordinates. Therefore, two sites can be compared using both perspectives, that is, estimating the differences in species composition using an index that uses the number of shared species (e.g., $\beta$-diversity or similarity indices), and estimating the geographical or Euclidean distance separating the sites. In this study, we used the Mantel test (Mantel 1967) to evaluate the correlation between the two matrices. The statistics of the Mantel test are standardized to $r$. Since each element in both matrices is not independent, the significance of $r$ was evaluated using permutations. This was done by constructing a reference distribution $r_{\mathrm{D}}$, which is obtained by randomly reassigning the similarity value between sites to a different distance and repeating the calculation of $r$. In this study, 1,000 permutations of the geographical distance matrix were used. The Jaccard index ( $\mathrm{J}$ ) was used as a measure of similarity between sites to calculate the biological matrix, and Euclidean distance was used to calculate the spatial distance matrix. The Jaccard index was expressed as $1-\mathrm{J}$ to obtain a measure that reflects the expected pattern of full similarity $1-\mathrm{J}=1$ and dissimilarity $1-\mathrm{J}=0$ (Rivadeneira et al. 2002). The analysis was performed with the computer program PC-ORD (McCune and Mefford 1999) using 1,000 permutations for the Monte Carlo method as a procedure to obtain the distribution of random data $r_{\mathrm{D}}$.

\section{Distribution ranges and latitudinal breaks in species diversity patterns}

Data matrices were produced with the presence and absence of subtidal and intertidal species along the latitudinal axis. To identify latitudinal breaks in species richness, we perform a hierarchical cluster analysis using UPGMA as linkage method and 1 - Jaccard similarity coefficients as distance metric (Ojeda et al. 2000) using 
Table 1 Species richness, sites and sampling dates of intertidal (Int) and subtidal (Sub) fishes (<35 m deep)

\begin{tabular}{|c|c|c|c|c|}
\hline Site & Latitude & Int richness & Sub richness & Sampling date \\
\hline Iquique & $20^{\circ} \mathrm{S}$ & 13 & 101 & 1997, May 1998 to May 1999 \\
\hline Caleta Errázuriz & $23^{\circ} \mathrm{S}$ & 13 & 100 & July 1996 to November 1997 \\
\hline Carrizal Bajo & $28^{\circ} \mathrm{S}$ & 14 & 99 & July 1996 to November 1997 \\
\hline Coquimbo & $30^{\circ} \mathrm{S}$ & 14 & 98 & March 1989 to September 1990 \\
\hline Los Molles & $32^{\circ} \mathrm{S}$ & 19 & 102 & March 1994 to July 1996 \\
\hline Las Cruces & $33^{\circ} \mathrm{S}$ & 18 & 101 & 1997 to 2005 (bimonthly) \\
\hline Concepción & $36^{\circ} \mathrm{S}$ & 17 & 98 & September 1998 to January 1999 \\
\hline Corral & $39^{\circ} \mathrm{S}$ & 13 & 103 & 1975 to 1976 \\
\hline Llanquihue & $41^{\circ} \mathrm{S}$ & 10 & 81 & 1987, 1991 and 1992 \\
\hline Chiloé & $43^{\circ} \mathrm{S}$ & 8 & 80 & January 1960 to April 1975 \\
\hline Aysén & $45^{\circ} \mathrm{S}$ & 6 & 70 & October 1995, November 1992 \\
\hline Puerto Natales & $51^{\circ} \mathrm{S}$ & 4 & 66 & October to November 1996 \\
\hline Punta Arenas & $53^{\circ} \mathrm{S}$ & 4 & 65 & January to July 1980, April 1992 \\
\hline Navarino Island & $55^{\circ} \mathrm{S}$ & 4 & 81 & 1987 to 1988 \\
\hline Total richness & & 20 & 151 & \\
\hline
\end{tabular}

At each study site along the Chilean coast.

Systat $^{\oplus}$ v12 software. Validity of the optimal clustering configuration was evaluated by bootstrapping 1,000 times the presence/absence matrix and estimating at each step the root mean square standard deviation (RMSSTD) across sites within each cluster. The similarity recorded at the minimum values of RMSSTD can be regarded as the similarity level greater than that expected by chance alone. In addition, using 1 - Jaccard's coefficient, we plotted the similarity between pairs of adjacent sites along the coast of Chile for both fish assemblages. Finally, we also illustrate the location where species evidenced limit to their range distributions by calculating the index $\Delta S\left(\Delta S=S_{\text {Lat } i}-S_{\text {Lat } i+1}\right)$ between site at the latitude $i$ with the southward adjacent site located at the latitude $i+1$. Thus, $\Delta S=1$ when a species is present in the northern but is absent in the adjacent southward site and $\Delta S=-1$ when the species is absent in the northern site but present in the southward site. Plotting positive and negative $\Delta S$ values along latitude, we explore the location of southern limit to northern species and northern limits of the southern species.

\section{Relationship of biogeographic patterns with environmental variables}

There are few sources of environmental information along the Chilean coast over the spatial scales involved in this study; therefore, it was difficult to obtain exact matching data in terms of study period or spatial location of the study sites along the coast (also see Astorga et al. 2003; Valdovinos et al. 2003; Fernández et al. 2009). Thus, historical records of annual mean sea surface temperatures (SST) estimated for each degree of latitude from of each study site were compiled from the NOAA monthly data set (http://ferret.wrc.noaa.gov/Ferret/). Chlorophyll-a concentrations (Chl-a, $\mathrm{mg} \mathrm{m}^{-3}$ ) estimated for the first $12 \mathrm{~km}$ cross-shore per degree of latitude from each study front was calculated by using 8-day averages, available from SeaWiFs satellite images between 1997 and 2000 (Thomas 1999; Fernández et al. 2009). The continental shelf area was relatively estimated by digitizing a 1:106 scale Lambert Zenithal Azimuthal equal area projection map down to the 200-m isobath (Astorga et al. 2003). For intertidal species, this area may represent the area where juvenile stages develop, while for subtidal species, it represents the habitat where they concentrate, providing a relatively good representation of the biogeographical pattern of fish distribution in Chilean coastal habitats.

The direction and magnitude of each bivariate relationship between environmental variables and species richness was estimated with the Pearson product-moment correlation coefficient, using the Bonferroni correction. Subsequently, the contribution of each environmental variable to the total variance of the spatial diversity variation pattern was evaluated using the squared semi-partial correlation $\left(\mathrm{sr}^{2}\right)$ in a multiple regression model (Tabachnik and Fidell 1989; Astorga et al. 2003).

When the sum of the pure effect of each variable (i.e., pure effect measured by the squared semi-partial correlation $\mathrm{sr}^{2}$ and represented by the symbol $\Sigma$ in the tables) corresponds to the coefficient of determination $\left(r^{2}\right)$ of the regression model that includes all of these variables, we can conclude that the environmental effects are additive. However, any difference between $\mathrm{sr}^{2}$ 
and $r^{2}$ can be attributed to synergistic effects or interaction between environmental variables.

In the case of multiple relationships, and given that diversity is the result of interactive processes, the data have been processed on a logarithmic scale, thus allowing for the application of regression models under the assumption of additivity of the effects involved in the analysis. Since multicollinearity between environmental variables is possible in this multiple regression analysis (e.g., SST with chlorophyll concentration), automatic methods were not applied in the selection of regression models (e.g., stepwise). Instead, models were developed sequentially, by manually adding variables as the $r^{2}$ value increased from the previous model. In addition, we compared all resulting models using the AIC and weighted AIC $\left(\mathrm{AIC}_{\mathrm{w}}\right)$ to parsimoniously order the selected models. In this study, we only report the models with one to five parameters, maximizing $r^{2}$ with their corresponding $\mathrm{AIC}$ and $\mathrm{AIC}_{\mathrm{w}}$.

\section{Results}

Latitudinal gradient in species richness

In total, 171 fish species were recorded from the 14 studied sites, of which 20 were intertidal (residents and transients) and 151 were subtidal (Table 1). Overall, the best fit between species richness and latitude was attained using a third order polynomial regression (Table 2). Richness decreased markedly as latitude increased, although not throughout the entire range. Furthermore, the latitudinal pattern varied slightly between intertidal and subtidal fish. The maximum values of richness were observed around $30^{\circ}$ and $35^{\circ} \mathrm{S}$, both in intertidal and subtidal habitats (Figure 1B). In the north, the values decreased slightly for intertidal fish, whereas they are similar and consistent throughout northern and central Chile for subtidal fish. For both habitats, species richness decreased steadily towards the southern end of the Chilean coast from their respective observed maximums. Additionally, a slight increase in richness of subtidal species was observed in the southern end of Chile (Figure 1B).

Table 2 Summary of regression analysis of first, second and third order between fish species richness and latitude

\begin{tabular}{lccccc}
\hline Habitat & Model & $\boldsymbol{P}$ value & $\boldsymbol{r}^{2}$ & AIC & $\mathbf{A I C}_{\mathbf{w}}$ \\
\hline Intertidal & Lineal & $<0.001$ & 0.70 & -7.883 & 0.003 \\
& Quadratic & $<0.001$ & 0.90 & -14.104 & 0.070 \\
& Cubic & $<0.001$ & 0.93 & -19.273 & 0.927 \\
Subtidal & Lineal & $<0.001$ & 0.67 & -42.130 & 0.001 \\
& Quadratic & 0.001 & 0.71 & -51.166 & 0.127 \\
& Cubic & 0.001 & 0.81 & -55.022 & 0.872
\end{tabular}

All models are significant and ranked in terms of the coefficient of determination $\left(r^{2}\right)$, Akaike information criteria (AIC) and weighted AIC $\left(\mathrm{AIC}_{\mathrm{w}}\right)$ of the respective model.

\section{Spatial scales of autocorrelation of alpha diversity}

The richness of both intertidal and subtidal fish showed the existence of a latitudinal gradient between the study sites. This was reflected by positive correlations in species richness at distances $<1,000 \mathrm{~km}$, while the autocorrelations were negative at greater distances between sites. It can be stated that for both intertidal and subtidal fish, there is a significant decline in richness as the distance between sites increases, that is, nearby sites $(<1,000 \mathrm{~km})$ have similar numbers of species, while distant sites $(>1,000 \mathrm{~km})$ have different numbers of species (Figure 2A).

\section{Distance decay in similarity of species composition}

There is a clear pattern of decline in similarity from short to longer distances between sites in both intertidal and subtidal fish (Figure 2B). This was reflected by negative values for the overall Mantel coefficient of -0.79 for intertidal fish and of -0.81 for subtidal fish. In both cases, it was seen that despite the large distances involved, total dissimilarity in species richness was never recorded between the pairs of sites.

\section{Distribution ranges and latitudinal breaks in species diversity patterns}

Application of an UPGMA cluster analysis on the presence/absence data of intertidal fishes along the Chilean coast indicated three statistically significant latitudinal biogeographic regions: one ranging from $20^{\circ}$ to $36^{\circ} \mathrm{S}$, and the others from $39^{\circ}$ to $43^{\circ} \mathrm{S}$ and from $45^{\circ}$ to $55^{\circ} \mathrm{S}$ (Figure 3A). In general, 1 - Jaccard coefficients between adjacent sites showed highest values within each latitudinal cluster (Figure 3A), while the decrease in these similarity coefficients could be ascribed to limits in the distributions for the southern and northern species at $30^{\circ}$ to $32^{\circ} \mathrm{S}$ and at $36^{\circ}$ to $39^{\circ} \mathrm{S}$ (Figure $3 \mathrm{C}$ ). In the case of subtidal fishes, we identify five statistically significant regions of different latitudinal extensions: the longest region spanned from $20^{\circ}$ to $36^{\circ} \mathrm{S}$ (cluster 1 in Figure 3B); from $39^{\circ} \mathrm{S}$ to $55^{\circ} \mathrm{S}$, there is successive cluster of reduced spatial extension; the separation between the northern region $20^{\circ}$ to $36^{\circ} \mathrm{S}$ may be is associated lowest 1 - Jaccard coefficients recorded between adjacent sites located between $36^{\circ}$ to $41^{\circ} \mathrm{S}$ (Figure $3 \mathrm{~B}$ ); these low similarity values are associated with the northern limits in the distribution of southern species at $36^{\circ}$ to $39^{\circ} \mathrm{S}$ and the southern limits of northern species at the $39^{\circ}$ to $41^{\circ} \mathrm{S}$ (Figure 3D).

\section{Relationship of biogeographic patterns with environmental variables}

As a first approach, we performed an exploratory analysis based on the Pearson product-moment correlation coefficient so as to detect significant associations between variables. In this analysis, latitude was significantly 


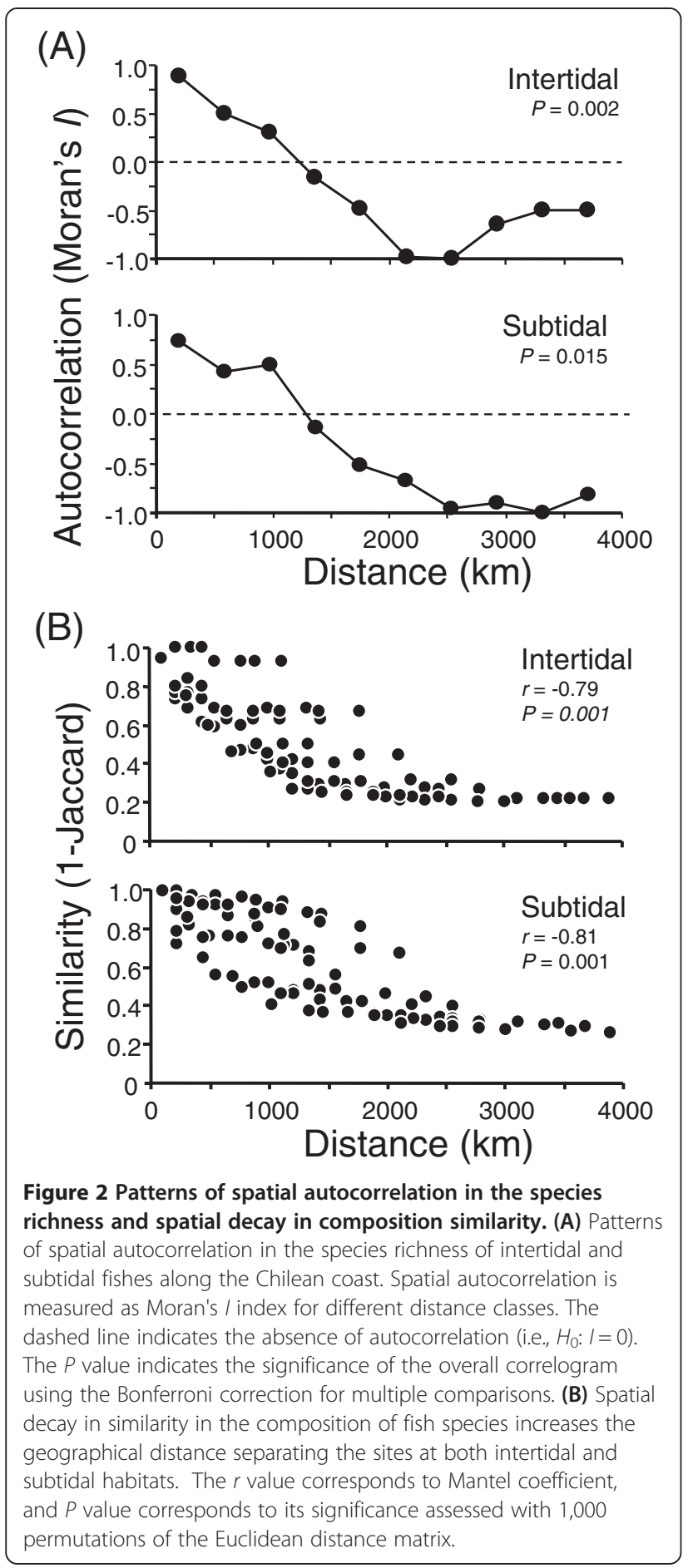

associated with both intertidal and subtidal fish richness, while for chlorophyll-a (satellite data), no significant linear association was observed in either of the two groups of fish (Figure 4). Finally, the continental shelf area showed a negative association, whereas SST was positively correlated with richness in both intertidal and subtidal fishes (Figure 4).
In the case of intertidal fishes, there was no significant relationship between species richness and chlorophyll-a (incorporating the squared component), or with any other environmental variable (Table 3). As for subtidal fish species, latitude and temperature had a significant influence on geographic variation in terms of richness (Table 3). These results do not agree with those obtained with the simple linear correlation analysis performed for the same environmental variables (see Figure 4), which suggests possible interactions between the variables under study. This can be explored by comparing the sum of the individual values of $\mathrm{sr}^{2}$ with the $r^{2}$ of the multiple regression model that includes all of the variables. Regarding the richness of rocky intertidal fish, the observed values in the multiple regression model were as follows: $\mathrm{sr}^{2}=0.15$, while $r^{2}=0.908$ (Table 3). This creates a difference of about 0.75 in the explanatory power of the environmental variables between the two correlation models used. In the sequential adjustment of the models, it was possible to observe that the complete model (i.e., five parameters) was significant for intertidal fish with $r^{2}=0.908$ (Table 4) and, as expected, similar to that obtained in the multiple regression analysis of $r^{2}=$ 0.91 (Table 3). In the case of sequential adjustment, temperature explains much of the variation of fish richness $\left(r^{2}=0.820\right.$, Table 4$)$, followed by the continental shelf area, which explains a slightly lower portion with $r^{2}=0.766$, and which increases the coefficient of determination to $r^{2}=0.843$ when both variables are included in the two-parameter model. Inclusion of new variables (e.g., latitude in the three-parameter model) did not cause a substantial increase in the coefficient of determination (Table 4).

For subtidal fish, it was observed that the most important variable was the continental shelf area with $r^{2}=$ 0.745 (Table 4). This slightly increased when the squared component of chlorophyll-a $\left(\mathrm{Chl}-\mathrm{a}^{2}\right)$ was added (to $r^{2}=$ 0.799). However, the coefficient of determination substantially increased to 0.862 when latitude and temperature were included (i.e., four-parameter model).

\section{Discussion}

It is clear that richness of littoral fishes on the Chilean coast is not constant along the latitudinal axis and, overall, a progressive decrease in richness toward higher latitudes can be observed. This general pattern was also described by Ojeda et al. (2000) for Chilean coastal bony fish and Chondrichthyes. For both of these groups, richness values are relatively constant from northern Chile to about $40^{\circ}$ to $42^{\circ} \mathrm{S}$, from which there is a marked decrease southward. In the current study, in agreement with Ojeda et al. (2000), a marked decrease of species south of ca. $40^{\circ} \mathrm{S}$ was observed, as well as a constant richness of subtidal fish north of this point. However, for 

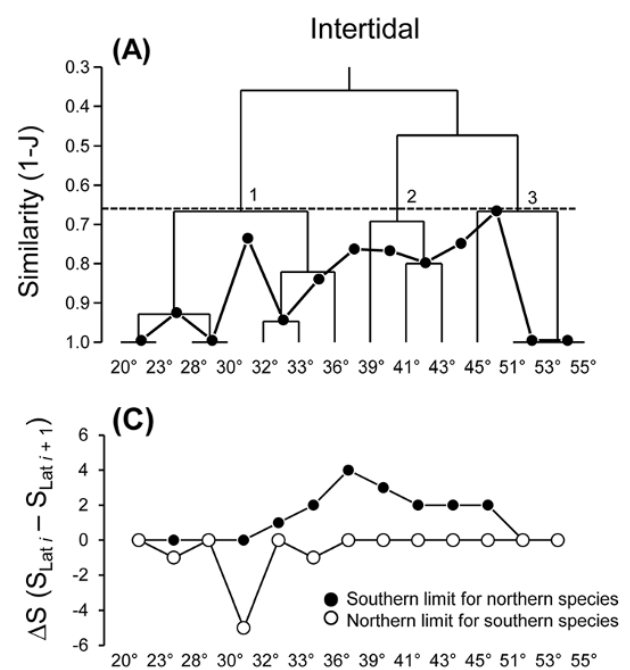

Latitude ( $\left.{ }^{\circ} \mathrm{S}\right)$
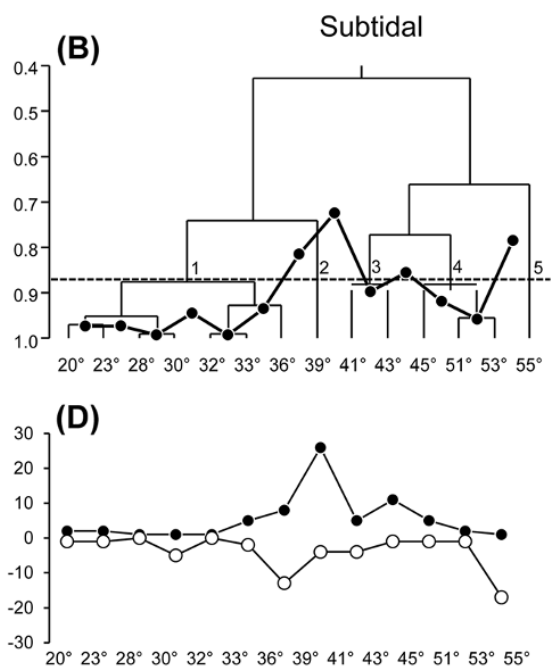

Latitude $\left({ }^{\circ} \mathrm{S}\right)$

Figure 3 Hierarchical cluster analysis using UPGMA based on presence/absence data of fishes along the Chilean coast. For (A) intertidal and (B) subtidal habitats. Bold line and filled dots superimposed are the 1 - Jaccard similarity coefficients between adjacent sites; the dashed lines within each dendrograms represent the similarity level with lowest RMSSTD representing the optimal cluster configurations resulting from bootstrapping (see methods). The figure also shows the turnover index $\Delta S$ for (C) intertidal and (D) subtidal fish species across adjacent study sites, where the southern limit for northern species (filled circles) and the northern limit for southern species (open circles) are shown.

intertidal fish, richness peaked between $32^{\circ}$ and $36^{\circ} \mathrm{S}$, which is a pattern that has been previously recorded for intertidal peracarids at mid-latitudes along the Chilean coast (Thiel 2002; Rivadeneira et al. 2011). From this zone of maximum richness, the numbers of species decrease both northward and southward. Such decrease is more pronounced at higher latitudes. This result suggests that although overall fish richness decreases with increasing latitude, particular assemblages associated with intertidal habitats may show breaks in this trend.

These peaks of intertidal fish species richness at temperate latitudes, where richness can apparently vary without a particular trend at intermediate latitudes, could be widespread in fish living in these environments. Prochazka et al. (1999) collected bibliographic information on intertidal fish from different temperate and tropical regions of the world, and despite the possible bias and lack of representation associated with such diverse bibliography, there is still no clear indication of a decrease in richness with increasing latitude, at least not at intermediate latitudes. This particular pattern may be the result of underlying processes related to the particular and highly variable conditions of the intertidal environment, specifically tide pools. In this environment, the observed pattern emerges from the specific characteristics of the resident fish fauna, whose species are usually small and cryptic in habit and coloration. These characteristics are generally considered to be specialized to intertidal life (Horn et al. 1999). Similarly, other marine organisms have shown variations in the pattern of decreasing species at higher latitudes. For example, it has been reported that the total number of sublittoral benthic macroalgae and invertebrate species tends to increase steadily towards the south of Chile (Santelices 1980; Brattström and Johanssen 1983; Lancellotti and Vásquez 2000; Fernández et al. 2009; Rivadeneira et al. 2011). For macroalgae, this pattern results from an increase in the contribution of species of subantarctic origin toward the south (Santelices 1980).

Our results show that both richness and species composition between study sites are structured. Richness is positively autocorrelated up to about $1,000 \mathrm{~km}$ of separation between sites for both fish assemblages. This reveals that the richness of sites separated by $>1,000 \mathrm{~km}$ has no dependencies, thus indicating the spatial range of influence of local richness values. As with the number of species, similarity between sites decreases depending on the distance between them. However, no paired comparison between locations showed complete dissimilarity of fish fauna, even between the end locations of the range of study. This can be explained by the presence of species that are distributed all along the Chilean coast and which are therefore common to all locations. Among these species, both Chondrichthyes and bony fish are found in the subtidal environment, while these widespread species are represented only by bony fish in the intertidal zone. Certainly, the pattern generated in intertidal and subtidal fish corresponds to a balance between species 

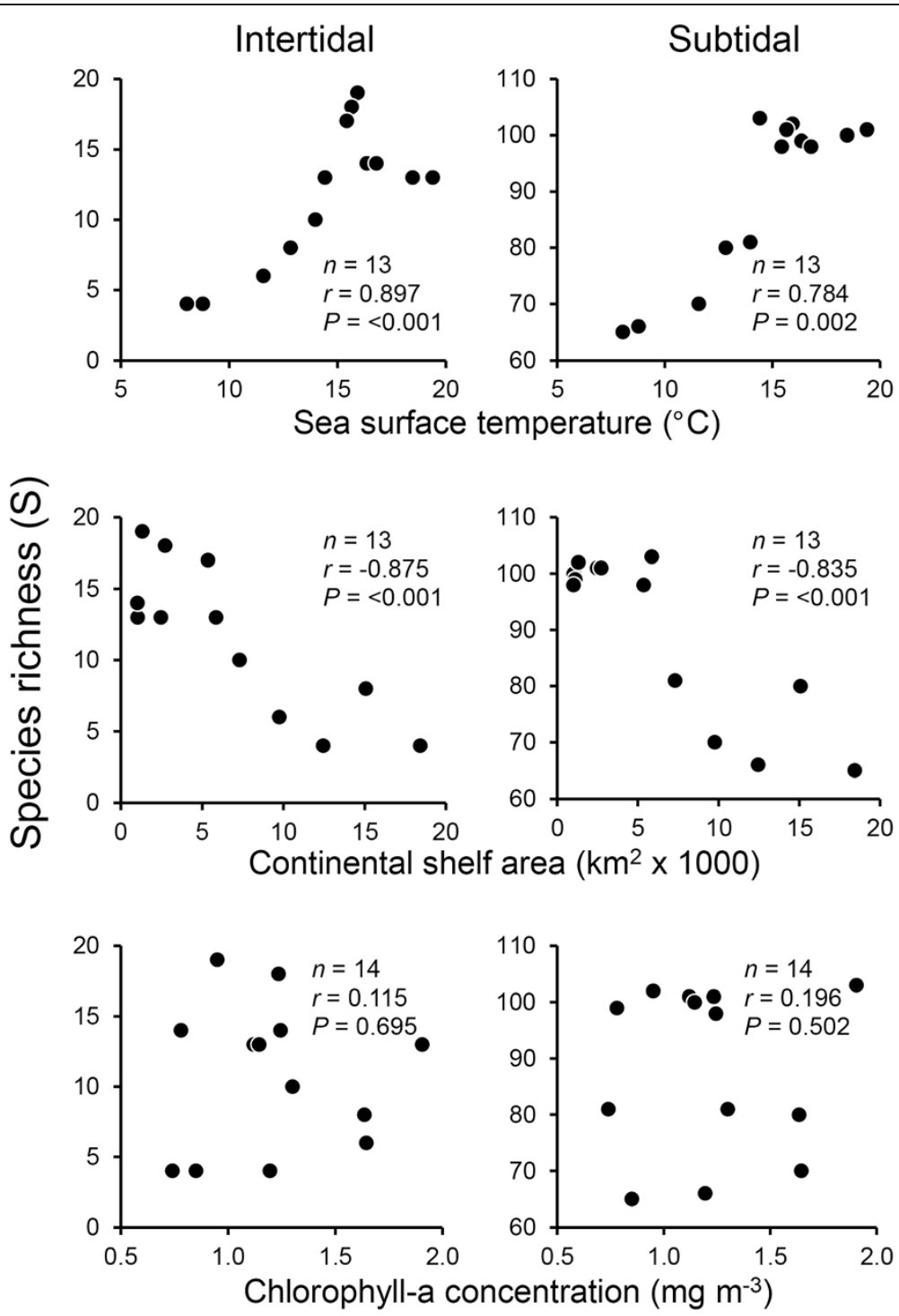

Figure 4 Relationship between fish richness with the environmental variables. Sea surface temperature, continental shelf area and chlorophyll-a concentration along the Chilean coast.

maintenance, loss, and entry, in addition to the presence of endemic species with a reduced distribution range (Ojeda et al. 2000).

The fact that there are latitudinal breaks in intertidal fish richness with a progressive decline in the number of species above $33^{\circ} \mathrm{S}$ and a steady decline in species turnover from north to south indicates that these patterns emerge more from species loss than from changes in the specific composition. However, the precise increase of richness at $33^{\circ} \mathrm{S}$ may be due to the appearance of species endemic to the Chilean intertidal zone starting at $20^{\circ} \mathrm{S}$ (i.e., Helcogrammoides chilensis (Cancino 1960)) and $32^{\circ} \mathrm{S}$ (e.g., Bovichthys chilensis Regan, 1913; Auchenionchus microcirrhis (Valenciennes 1836); Helcogrammoides cunninghami (Smitt 1898). Please refer to Appendix one in Ojeda et al. 2000), which is a similar pattern found for intertidal peracarids, and due to the possible overlap of northern and southern species (see Thiel 2002). At the other end of the latitudinal gradient, the fact that richness stabilizes and turnover substantially increases starting at $48^{\circ}$ $\mathrm{S}$ may be due to the entry of new species originating in the south (e.g., Agonopsis chiloensis (Jenyns 1840), Notothenia spp.). These new species build up assemblages different from those recorded at lower latitudes (e.g., from $33^{\circ}$ to $46^{\circ}$ $\mathrm{S})$, which can be due to the possible effect of the dispersive barrier of the Peninsula Taitao around $48^{\circ} \mathrm{S}$, as it has also been observed for other invertebrate marine taxa (Häussermann and Försterra 2005; Wichmann et al. 2012). Regarding subtidal fish, the break at $39^{\circ} \mathrm{S}$ suggests that there is an area of high diversity and low 
Table 3 Squared semi-partial correlation and multiple correlation of spatial and environmental variables

\begin{tabular}{|c|c|c|c|c|c|c|c|c|c|c|}
\hline \multirow[b]{2}{*}{ Habitat } & \multirow[b]{2}{*}{ Variable } & \multicolumn{6}{|c|}{ Squared semi-partial correlation } & \multicolumn{3}{|c|}{ Multiple regression } \\
\hline & & $d f$ & Parameter & SE & $T$ & $P$ value & $s r^{2}$ & $F_{(1,5)}$ & $P$ value & $r^{2}$ \\
\hline \multirow[t]{6}{*}{ Intertidal } & Lat & 1 & 0.01 & 0.01 & 1.01 & 0.35 & 0.01 & 13.81 & $<0.01$ & 0.908 \\
\hline & Chl-a & 1 & -0.29 & 0.18 & -1.65 & 0.14 & 0.04 & & & \\
\hline & Chl-a $\mathrm{a}^{2}$ & 1 & 0.10 & 0.06 & 1.75 & 0.12 & 0.04 & & & \\
\hline & Area & 1 & 0 & 0 & -1.33 & 0.23 & 0.02 & & & \\
\hline & SST & 1 & 0.03 & 0.02 & 1.61 & 0.15 & 0.03 & & & \\
\hline & & & & & & & $\Sigma \mathrm{sr}^{2}=0.15$ & & & \\
\hline \multirow[t]{6}{*}{ Subtidal } & Lat & 1 & 0.04 & 0.02 & 2.42 & 0.05 & 0.07 & 15.51 & $<0.01$ & 0.917 \\
\hline & Chl-a & 1 & -0.97 & 0.45 & -2.16 & 0.07 & 0.05 & & & \\
\hline & Chl-a ${ }^{2}$ & 1 & 0.31 & 0.15 & 2.12 & 0.07 & 0.05 & & & \\
\hline & Area & 1 & -0.02 & 0.01 & -2 & 0.09 & 0.05 & & & \\
\hline & SST & 1 & 0.15 & 0.05 & 2.79 & 0.03 & 0.09 & & & \\
\hline & & & & & & & $\Sigma \mathrm{sr}^{2}=0.32$ & & & \\
\hline
\end{tabular}

Squared semi-partial correlation $\left(\mathrm{sr}^{2}\right)$ and multiple correlation $\left(r^{2}\right)$ of spatial (Lat, latitude), and environmental variables (SST, sea surface temperature; Area, continental shelf area; and the linear ( $\mathrm{Chl}-\mathrm{a})$ and quadratic component $\left(\mathrm{Chl}^{2} \mathrm{a}^{2}\right.$ ) of chlorophyll-a) on the pattern of geographic variation in species richness of fish inhabiting the intertidal and subtidal along the Chilean coast. The sum $\Sigma$ is the sum of the squared semi-partial correlation for each variable included in the regression model. $P$ values in italics indicate a significant effect of a given parameter. $\mathrm{SE}$, standard error.

turnover between $36^{\circ}$ and $41^{\circ} \mathrm{S}$, with a significant level of endemic species. The observed decrease in species richness south of $38^{\circ}$ to $40^{\circ} \mathrm{S}$ is primarily due to a marked loss of species of subtropical origin, represented mainly by herbivores (e.g., Aplodactylus punctatus Valenciennes, 1832). However, specific turnover substantially increases, which is possibly the combined effect of both the loss and entry of new species (but to a lesser extent to the amount lost) of sub-Antarctic origin, mainly from the Zoarcidae and Nototheniidae families (Ojeda et al. 2000). A similar pattern has also

Table 4 Analysis of the order of entry into the model of each explanatory variable and its importance

\begin{tabular}{ccccccccc}
\hline Parameters & $\boldsymbol{r}^{2}$ & AIC & AIC $_{\mathbf{w}}$ & Variables included in the models \\
\hline Intertidal & & & & & & & & \\
1 & 0.820 & -86.2 & 0.212 & SST & & & & \\
2 & 0.843 & -86.0 & 0.192 & SST & Area & & & \\
3 & 0.866 & -86.1 & 0.201 & SST & Area & Lat & & \\
4 & 0.872 & -84.6 & 0.095 & SST & Area & Lat & Chl-a ${ }^{2}$ & \\
5 & 0.908 & -86.9 & 0.300 & SST & Area & Lat & Chl-a ${ }^{2}$ & Chl-a \\
Subtidal & & & & & & & & \\
1 & 0.745 & -55.8 & 0.028 & Area & & & & \\
2 & 0.799 & -56.9 & 0.049 & Area & Chl-a & & & \\
3 & 0.827 & -56.9 & 0.049 & Area & Chl-a ${ }^{2}$ & SST & & \\
4 & 0.862 & -57.8 & 0.076 & Area & Chl- $a^{2}$ & SST & Lat & \\
5 & 0.917 & -62.5 & 0.799 & Area & Chl- $a^{2}$ & SST & Lat & Chl-a \\
\hline
\end{tabular}

On geographic variation of intertidal and subtidal fish richness along the Chilean coast (Lat, latitude; SST, sea surface temperature; Area, continental shelf area; Chl-a, chlorophyll-a lineal; $\mathrm{Chl}^{2} \mathrm{a}^{2}$, chlorophyll-a quadratic). The models were ordered in parsimonious form using the Akaike information criteria (AIC) and weighted $\mathrm{AIC}\left(\mathrm{AIC}_{\mathrm{w}}\right)$. been documented for polychaetes (see Moreno et al. 2006).

The biogeographical aspects of the fish fauna of the eastern South Pacific had already been discussed by Mead (1970), who noted that there is no such fish fauna that originated on these shores. Accordingly, we can observe that it sprung from the colonization and adaptation of various taxa of tropical and subantarctic origin. In addition, Mead (1970) proposed that the observed pattern of species decline at higher latitudes was mainly due to the absence of species of subtropical origin, primarily herbivorous fish belonging to the advanced Perciformes. The possible explanation for this was lack of time for these taxa to have evolved and adapted to the cold temperate conditions since the last glacial period. However, there is evidence of organisms within the advanced Perciformes that have in fact been able to adapt to cold temperate conditions, being these fish strict carnivores or omnivores. Therefore time is not a sufficient explanation for the observed pattern within the advanced Perciformes, with particular restrictions on herbivore feeding modes, which are more likely to occur in temperate and cold waters (see Floeter et al. 2005).

One of the most assessed and discussed causal mechanisms proposed to explain the decrease in species richness toward high latitudes relates to the particular diet of the fishes. Since diet is subject to physiological restrictions based on water temperature, energetic requirements of herbivore fishes can be affected by low temperature of polar waters (see Floeter et al. 2005; Pulgar et al. 2005; Behrens and Lafferty 2007). Nevertheless, these studies do not agree on the net effect of temperature on fitness or on the dietary preference of omnivorous fish, although they 
do highlight the importance of the combined effect of temperature and type of diet (i.e., herbivorous, omnivorous, and carnivorous) on metabolic rate, rate of intake, and assimilation capability. For example, Pulgar et al. (2005) recorded that the omnivorous Girella laevifrons (Tschudi 1846) tended to prefer a diet of algae over an animal diet at lower temperatures, arguing that metabolic rate decreases at low-temperature degrees. However, both Floeter et al. (2005), who studied the surgeonfish Acanthurus bahianus Castelnau, 1855, as well as Behrens and Lafferty (2007), who studied Girella nigricans (Ayres, 1860), noted that decreases in temperature worked against those fish with herbivorous diets, thus being an omnivorous diet more efficient at low temperatures. This particular herbivore restriction suggests a selection against fish whose diet consists mainly of algae and could mostly explain the latitudinal pattern of decline in the richness recorded for this group of fish. This also coincides with declines in overall abundances of these fishes (Meekan and Choat 1997).

Some of the breaks recorded in the biogeographic patterns are consistent with changes in the environmental system of the Chilean coast. For example, the change in the width of the continental shelf at $33^{\circ} \mathrm{S}$ coincides with a break in both the number and composition of species. This has also been described for benthic molluscs on South Pacific coasts (Valdovinos et al. 2003), where changes in the geomorphology of the continental shelf south of $40^{\circ} \mathrm{S}$ latitude constitute the variable that best explains the increased richness recorded. However, our results, similar to Rivadeneira et al. (2011) regarding peracarids, indicate a decrease in richness with an increase in continental shelf area. The correlation between diversity patterns and factors such as the geomorphology of the continental shelf justifies the use of a biogeographic perspective, since it generally holds that much of the variation in species richness, and abundance can be explained by environmental variables. Nevertheless, as evidenced by our results, such variation could be the effect of several types of variables acting together. Therefore, it cannot be explained by simply adding the effects involved but rather by identifying the interactions between the environmental variables studied. Correlations of these variables with a common variable that has not been considered in this study would also contribute to elucidating what triggers richness variation. This raises the need for studies that include factors other than those discussed in this paper. For example, Colton and Swearer (2012) studied the coastal fish fauna of Victoria, Australia, and concluded that the particular conditions of currents, isotherms, and habitat discontinuities can determine the biogeographic breaks recorded in this area, also emphasizing the difficulty of attributing faunal breaks to single mechanisms. Meanwhile, Lucifora et al. (2012) showed the importance of oxygen concentration and oceanic fronts for the diversity of
Chondrichthyes over the continental shelf in the southwest Atlantic. Thus, the highest diversity levels were recorded close to oceanic fronts, where different water masses converge and generate enormous biological productivity, due to the entrance of nutrients into the photic zone of the water column caused by turbulent mixing (Acha et al. 2004).

\section{Conclusions}

Although our results suggest that environmental variables may simultaneously affect richness, the relative significance of each variable may differ between fish from different habitats. This is precisely what was observed between the two littoral environments studied. While temperature and shelf width were the main factors underlying variations in intertidal fish richness (both independently and in combination), shelf area mainly affected subtidal fish richness variations (independently and together with latitude and temperature).

\section{Competing interests}

The authors declare that they have no competing interests.

\section{Authors' contributions}

Data base: FPO. Analyzed the data: AHN and NAL. Wrote the paper: AHN, $\mathrm{NAL}$, and FPO. All authors read and approved the final manuscript.

\section{Acknowledgments}

We are grateful to Bernardo Broitman for providing SST, Chl-a, and areal data and to Martin Thiel for valuable comments and suggestions on the manuscript. This study was funded by several FONDECYT projects and FONDAP-FONDECYT grant 15010001 CASEB to FPO. NAL acknowledges financial support from CONICYT-FONDECYT 1090624 and PIA-CONICYT ANILLOS ACT-132. AHN is currently funded by a CONICYT doctoral fellowship.

\section{Author details}

'Departamento de Ecología, Facultad de Ciencias Biológicas, Pontificia Universidad Católica de Chile, Almeda 340, Casilla 114-D, Santiago, Chile. ${ }^{2}$ Laboratorio de Ecología \& Cambio Climático, Centro de Investigaciones en Ciencias Ambientales, Facultad de Ciencias, Universidad Santo Tomás, Ejército 146, Santiago, Chile.

Received: 14 August 2013 Accepted: 31 December 2013 Published: 26 March 2014

\section{References}

Acha EM, Hw Mianzan RA, Guerrero MF, Bava J (2004) Marine fronts at the continental shelves of austral South America: physical and ecological processes. J Mar Syst 44:83-105, doi:10.1016/j.jmarsys.2003.09.005

Ahumada RB, Pinto LA, Camus PA (2000) The Chilean coast. In: Sheppard CRC (ed) Seas at the millenium: an environmental evaluation. Regional Chapters, vol I. The Americas and West Africa, Europe. Pergamon, Amsterdam, pp 699-717

Angel A, Ojeda FP (2001) Structure and trophic organization of subtidal fish assemblages on the northern Chilean coast: the effect of habitat complexity Mar Ecol Prog Ser 217:81-91

Astorga A, Fernández M, Lagos NA, Boschi E (2003) Two oceans, two taxa and one mode of development: latitudinal diversity patterns of South American crabs and test for causal processes. Ecol Lett 6:420-427

Behrens M, Lafferty KD (2007) Temperature and diet effects on omnivorous fish performance: implications for the latitudinal diversity gradient in herbivorous fishes. Can J Fish Aquat Sci 64:867-873

Berrios V, Vargas ME (2000) Estructura del ensamble de peces intermareales de la costa rocosa del norte de Chile. Revista De Biología Marina Y Oceanografía 35:73-81

Blackburn TM, Gaston KJ (1996) A sideways look at patterns in species richness, or why there are so few species outside the tropics. Biodivers Lett 3:44-53

Brattström H (1990) Intertidal ecology of the northernmost part of the Chilean archipelago. Report no. 50 of the Lund University Expedition 1984-1949. Sarsia 75:107-160 
Brattström H, Johanssen A (1983) Ecological and regional zoogeography of the marine benthic fauna of Chile. Report no. 49 of the Lund University Expedition 1984-1949. Sarsia 68:289-339

Broitman BR, Navarrete SA, Smith F, Gaines SD (2001) Geographic variations of the southeastern Pacific intertidal communities. Mar Ecol Prog Ser 224:21-34

Broitman BR, Véliz F, Manzur T, Wieters EA, Finke GR, Fornes PA, Valdivia N, Navarrete SA (2011) Geographic variation in diversity of wave exposed rocky intertidal communities along central Chile. Rev Chil Hist Nat 84:143-154

Camus PA (2001) Biogeografía marina de Chile continental. Rev Chil Hist Nat $74: 587-617$

Castilla JC, Lagos NA, Cerda M (2004) Marine ecosystem engineering by the alien ascidian Pyura praeputialis on a mid-intertidal rocky shore. Mar Ecol Prog Ser 268:119-130

Colton MA, Swearer SE (2012) Locating faunal breaks in the nearshore fish assemblage of Victoria, Australia. Mar Freshw Res 63:218-231

Dahl E (1960) The cold temperate zone in Chilean seas. Proc R Soc Lond B 152:631-633

Dell RK (1971) The marine Mollusca of the Royal Society expedition to southern Chile, 1958-1959. Records of the Dominion Museum 7:155-233

Fernández M, Astorga A, Navarrete SA, Valdovinos C, Marquet PA (2009) Deconstructing latitudinal species richness patterns in the ocean: does larval development hold the clue? Ecol Lett 12:601-611

Floeter SR, Behrens MD, Ferreira CEL, Paddack MJ, Horn MH (2005) Geographical gradients of marine herbivorous fishes: patterns and processes. Mar Biol 147:1435-1447

Gibson RN, Yoshiyama RM (1999) Intertidal fish communities. In: Horn MH, Martin KLM, Chotkowski MA (eds) Intertidal fishes, life in two worlds: 264-296. Academic Press, San Diego, California

Harrison S, Ross SJ, Lawton JH (1992) Beta diversity on geographic gradients in Britain. J Anim Ecol 61:151-158

Häussermann V, Försterra G (2005) Distribution patterns of Chilean shallow-water sea anemones (Cnidaria: Anthozoa: Actinaria, Corallimorpharia), with a discussion of the taxonomic and zoogeographic relationships between the actiniofauna of the South East Pacific, the South West Atlantic and the Antarctic. Sci Mar 69:91-102

Hernández-Miranda E, Ojeda FP (2006) Inter-annual variability in somatic growth rates and mortality of coastal fishes off central Chile: an ENSO driven process? Mar Biol 149:925-936

Horn MH, Martin KLM, Chotkowski MA (1999) Introduction. In: Horn MH, Martin KLM, Chotkowski MA (eds) Intertidal fishes, life in two worlds: 1-5. Academic Press, San Diego, California

Jaramillo E (1982) Taxonomy, natural history and zoogeography of sand beach isopod from the coast of southern Chile. Studies Neotropical Fauna and Environment 17:175-194

Koleff P, Gaston KJ (2002) The relationships between local and regional species richness and spatial turnover. Glob Ecol Biogeogr 11:363-375

Lancellotti DA, Vásquez JA (2000) Zoogeografía de macroinvertebrados bentónicos de la costa de Chile: contribución para la conservación marina. Rev Chil Hist Nat 73:99-129

Lopez De Casenave J, Marone L, Camus PA, Jaksic FM (2007) Escalas. In: Jaksic FM, Marone L (eds) Ecología de comunidades: 193-213, 2nd edn. Ediciones Universidad Católica de Chile, Santiago, Chile

Lucifora LO, García VB, Menni C, Worm B (2012) Spatial patterns in the diversity of sharks, rays, and chimaeras (Chondrichtyes) in the Southwest Atlantic. Biodivers Conserv 21:407-419

Magurran AE (2004) Measuring Biological Diversity. Blackwell Publishing, Oxford

Mantel NA (1967) The detection of disease clustering and a generalized regression approach. Cancer Res 27:209-220

Mccune B, Mefford MJ (1999) PC-ORD, Multivariate analysis of ecological data, Version 4. MjM Software Design, Gleneden Beach, OR, USA

Mead GW (1970) A history of South Pacific fishes. In: Wooster WS (ed) Scientific exploration of the South Pacific. Stanford Book N ${ }^{\circ}$ 309-017556, National Academy of Sciences, Washington DC, pp 236-251

Meekan MG, Choat JH (1997) Latitudinal variation in abundance of herbivorous fishes: a comparison of temperate and tropical reefs. Mar Biol 128:373-383

Miloslavich P, Klein E, Díaz JM, Hernández CE, Bigatti G et al (2011) Marine biodiversity in the Atlantic and Pacific coast of South America: knowledge and gaps. PLOS ONE 6:e14631

Moreno CA, Jara HF (1984) Ecological studies on the fish fauna associated with Macrocystis pyrifera belts in the south of Fueguian Islands, Chile. Mar Ecol Prog Ser 15:99-107
Moreno RA, Hernández CE, Rivadeneira MM, Vidal MA, Rozbaczylo N (2006) Patterns of endemism in south-eastern Pacific benthic polychaetes of the Chilean coast. J Biogeogr 33:750-759

Ojeda FP, Labra FA, Muñoz AA (2000) Biogeographic patterns of Chilean littoral fishes. Rev Chil Hist Nat 73:625-641

Pequeño G, Lamilla J, Lloris D, Rucabado J (1995) Comparación entre las ictiofaunas intermareales de los extremos austral y boreal de los canales patagónicos. Revista De Biología Marina Valparaiso (Chile) 30:155-177

Pérez-Matus A, Ferry-Graham LA, Cea A, Vásquez JA (2007) Community structure of temperate reef fishes in kelp dominated subtidal habitats of northern Chile. Mar Freshw Res 58:1069-1085

Prochazka K, Chotkowski MA, Buth DG (1999) Biogeography of rocky intertidal fishes. In: Horn MH, Martin KLM, Chotkowski MA (eds) Intertidal fishes, life in two worlds: 332-355. Academic Press, San Diego, California

Pulgar JM, Bozinovic F, Ojeda FP (2005) Local distribution and thermal ecology of two intertidal fishes. Oecologia 142:511-520

Qian H, Ricklefs RE, White PS (2005) Beta diversity of angiosperms in temperate floras of eastern Asia and eastern North America. Ecol Lett 8:15-22

Ricklefs RE (1987) Community diversity: relative roles of local and regional processes. Science 235:167-171

Rivadeneira MM, Fernández M, Navarrete SA (2002) Latitudinal trends of species diversity in rocky intertidal herbivore assemblages: spatial scale and the relationship between local and regional species richness. Mar Ecol Prog Ser 245:123-131

Rivadeneira MM, Thiel M, González ER, Haye PA (2011) An inverse latitudinal gradient of diversity of peracarid crustaceans along the Pacific Coast of South America: out of the deep south. Glob Ecol Biogeogr 20:437-448

Rodríguez P, Arita HT (2004) Beta diversity and latitude in North American mammals: testing the hypothesis of covariation. Ecography 27:547-556

Rosenzweig ML (1995) Species diversity in space and time. Cambridge University Press, Cambridge

Santelices B (1980) Phytogeographic characterization of the temperate coast of Pacific South America. Phycologia 19:1-12

Sebens KP, Paine RT (1979) Biogeography of the anthozoans along the west coast of South America: habitat, disturbance, and prey availability. Proceedings International Symposium of Marine Biogeography and Evolution of the Southern Hemisphere 2:219-273

Soininen J, Lennon JJ, Hillebrand H (2007) A multivariate analysis of beta diversity across organisms and environments. Ecology 88:2830-2838

Sokal R, Oden N (1978) Spatial autocorrelation in biology. 1. Methodology. Biol J Linn Soc 10:199-228

Tabachnik BG, Fidell LS (1989) Using multivariate statistics, 2nd edn. Harper and Row, New York

Thiel M (2002) The zoogeography of algae-associated peracarids along the Pacific coast of Chile. J Biogeogr 29:999-1008

Thiel M, Macaya E, Acuña E, Arntz W, Bastías H et al (2007) The Humboldt Current System of northern and central Chile: oceanographic processes, ecological interactions and socioeconomic feedback. Oceanogr Mar Biol 45:195-345

Thomas A (1999) Seasonal distributions of satellite-measured phytoplankton pigment concentration along the Chilean coast. J Geophys Res-Oceans 104:25877-25890

Valdovinos C, Navarrete SA, Marquet PA (2003) Mollusk species diversity in the Southeastern Pacific: why are more species towards the pole? Ecography 26:139-144

Varas E, Ojeda FP (1990) Intertidal fish assemblages of the central Chilean coast: diversity, abundance and trophic patterns. Rev Biol Mar Valparaíso 25:59-70

Wagenmakers EJ, Farrell S (2004) AIC model selection using Akaike weights. Psychon Bull Rev 11:192-196

Wartenberg D (1989) SAAP version 4.3: spatial autocorrelation analyses program. Exter softwares, NY. USA

Whittaker RH (1972) Evolution and measurement of species diversity. Taxon 21:213-251

Wichmann C-S, Hinojosa IA, Thiel M (2012) Floating kelps in Patagonian Fjords: an important vehicle for rafting invertebrates and its relevance for biogeography. Mar Biol 159:2035-2049

\section{doi:10.1186/0717-6317-87-2}

Cite this article as: Navarrete et al: Latitudinal diversity patterns of

Chilean coastal fishes: searching for causal processes. Revista Chilena de Historia Natural 2014 87:2. 